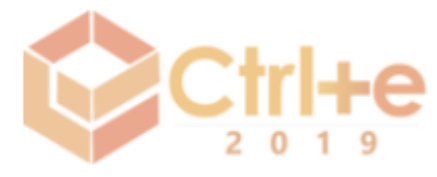

IV Congresso sobre Tecnologias na Educação (Ctrl+E 2019)

Recife, Pernambuco - Brasil

28 a 30 de agosto de 2019

\title{
Jogos digitais no Ensino de Física: Estudo do Movimento Bidimensional através da Ferramenta Scratch
}

\author{
Crelison Nelson H. Alves1, Gilvan Francisco da Silva1, Bruna Izabel da Silva1, \\ Enildo José dos S. Júnior1, Fabrício Filho O. Pereira1, Ana Paula T. B. Silva1, \\ Flávia Portela Santos1
}

1Unidade de Educação a Distância e Tecnologia - Universidade Federal Rural de Pernambuco (UFRPE)

Rua Dom Manoel de Medeiros, s/n - 52.171-900 - Recife - PE - Brazil

\{crelison.alves, Gilvan.francisco,bruna.izabel, enildo.santosjunior, fabr icio.pereira, ana.tbsilva, flavia.portela\} @ufrpe.br

\begin{abstract}
In order to minimize the difficulties experienced by students in their first contact with the concepts of the Physics discipline, we propose as a didactic tool the use of a game that can also be customized by the student himself. This work describes two games built with the Scratch platform, which is a project of the Lifelong Kindergarten Group of the Massachusetts Institute of Technology (MIT) Media Lab. With this platform it is possible to simulate physical phenomena and relate them to the most diverse contents in Physics from the construction of games (programming). In this case, we will use Scratch applied to kinematics in the study of two-dimensional motion.
\end{abstract}

Resumo. Visando minimizar as dificuldades vivenciadas por estudantes em seu primeiro contato com os conceitos da disciplina de Física, propõe-se como ferramenta didática a utilização de um jogo que pode ser também personalizado pelo próprio estudante. Este trabalho descreve dois jogos construídos com a plataforma Scratch, que é um projeto do Lifelong Kindergarten Group do Massachusetts Institute of Technology (MIT) Media Lab, com o qual é possivel, a partir da construção de jogos (programação), simular fenômenos físicos e relacioná-los aos mais diversos conteúdos em Física. Neste caso, utilizou-se o Scratch aplicado à cinemática no estudo do movimento bidimensional.

\section{Introdução}

O Ensino de Ciência na área de concentração de exatas e, em particular, de física conquistou o respeito e admiração da sociedade devido às novas descobertas científicas [Silva 2014]. Por outro lado, diversos fatores têm afastado esta ciência (enquanto conteúdo) dos estudantes do Ensino Médio. Nessa linha de ideias, [Moreira 2017] aponta alguns dos desafios atuais, que envolvem, desde o despreparo dos professores, as más condições de trabalho e o número reduzido de aulas nas escolas, à utilização de metodologia bancária de ensino (que tenta depositar conteúdos na cabeça do aluno) e focada no treinamento para as provas. A Física tem sido tratada como uma ciência 
acabada e limitada a resolução de questões, sem explorar a conexão entre os conceitos e as diversas aplicações no cotidiano, tornando-se desatualizada e não atrativa.

Nesse contexto, várias estratégias e metodologias têm sido investigadas para aproximar e despertar o interesse dos estudantes para o estudo das ciências, de forma a redirecionar a centralidade das aulas, tirando-a do professor e focando-a no estudante [Sasaki and Jesus 2017; Araújo and Abib 2003; Silva, Sales and Castro 2019]. Em especial, o jogo aplicado na educação tem se mostrado uma importante e emergente ferramenta educativa, de forma a potencializar aprendizagens nas mais diversas áreas do conhecimento e da vida dos indivíduos [Fardo 2013].

Este trabalho descreve a construção de um jogo, fazendo o uso de tecnologias digitais, para ser desenvolvido em sala de aula na disciplina de Física. O foco do estudo contempla os conceitos da cinemática, no movimento bidimensional, e na utilização da plataforma Scratch. Além da utilização do jogo visando o aprendizado, é possível apresentar os recursos básicos da ferramenta Scratch para que os estudantes modifiquem os jogos existentes e construam os seus próprios. Segundo a LEAD Project (2014), o Scratch tem um papel social de preparar os jovens para a velocidade com que o mundo tem se reinventado por meio da educação e criatividade, contrariando o ensino de Física tradicional e cartesiano, muitas vezes praticado nas escolas, tornando o processo de ensino e aprendizagem desconexo e, até mesmo, sem sentido.

[Lima 2010], refletindo sobre a importância da interação no processo de ensino e aprendizagem, destaca que a aprendizagem é um processo ativo e interativo, configurando, portanto, numa construção, em que o estudante constrói o conhecimento a partir de sucessivos desequilíbrios e reequilibrações. Nessa perspectiva, aluno levanta hipóteses sobre o conhecimento e pode incorrer em erros, que devem ser refletidos e trabalhados, dando lugar a novas hipóteses acerca do conhecimento. Nesse processo, o importante não é apenas conhecer o 'produto', o 'resultado' da aprendizagem, mas, sobretudo, o 'processo', ou seja, o caminho intelectual percorrido pelo estudante no ato de aprender. O professor tem um papel fundamental de promover 'interações' $\mathrm{e}$ 'conflitos cognitivos'. O jogo se enquadra, então, como uma ferramenta didática moderadora para ser desenvolvida nas atividades em sala de aula. Nesse sentido, esta proposta pretende unir os conhecimentos teóricos e a interatividade dos jogos como um facilitador no processo de ensino e aprendizagem.

\section{Justificativa Pedagógica}

A cinemática, segundo [Gaspar 2000], é a parte da Física que estuda e descreve os movimentos, sem se preocupar com as suas causas. Um lançamento oblíquo é um movimento que ocorre parte na direção vertical e parte na direção horizontal, exigindo maior compreensão na aplicação de conceitos estudados no movimento unidimensional. $\mathrm{O}$ estudo do movimento em duas dimensões envolve conceitos de posição, deslocamento, tempo, velocidade e aceleração; além da temática da conservação da Energia. Esses conteúdos são explorados nos primeiros contatos dos estudantes com a disciplina de Física e, por esta razão, devem ser construídos de forma planejada, pois esses momentos podem afastar ou aproximar os alunos em relação a esta ciência.

É nesse contexto que o presente estudo tem seu enfoque na cinemática e apresenta uma forma lúdica (divertida) de trabalhar esse conteúdo, fazendo-o através de um game. Ademais, a própria construção do jogo, uma vez que é realizada com uma ferramenta de fácil acesso e uso, possibilita que os próprios estudantes desenvolvam 
outras habilidades, como criatividade e programação, tendo para isso que se aprofundarem nos conceitos físicos para produzirem seus próprios jogos.

A aprendizagem de conceitos, no ensino de Física, proporcionada pela gamificação já tem se mostrado resultados significativos, quando comparada ao ensino tradicional [Silva, Sales and Castro 2019]. A concepção deste trabalho é de articular a utilização do jogo para melhoria da aprendizagem, defendida pela Teoria da Aprendizagem de Ausubel (2003), que propõe a valorização dos conhecimentos prévios dos estudantes. De acordo com Pelizzari et al. (2002, p. 40), tendo como base as ideias de Ausubel, "a construção das aprendizagens significativas implica a conexão ou vinculação do que o aluno sabe com os conhecimentos novos", associando-se o antigo ao novo. Ainda de acordo com esses autores, os estudantes devem realizar suas próprias aprendizagens significativas, que corresponde ao aprender a aprender. Desse modo, garantem-se "a compreensão e a facilitação de novas aprendizagens ao ter-se um suporte básico na estrutura cognitiva prévia construída pelo sujeito" [Pelizzari et al. 2002, p. 40].

\section{Metodologia}

Para a construção dos jogos foi usada como ferramenta de desenvolvimento a plataforma Scratch, programa idealizado pelo Lifelong Kindergarten Group do Massachusetts Institute of Technology (MIT) Media Lab. Ele é disponibilizado gratuitamente na internet e possibilita a criação de jogos e animações interativos, sendo possível trabalhar com imagens, fotos, música, criar desenhos e mudar a aparência.

Os jogos foram desenvolvidos em duas fases principais. A primeira fase contemplou o estudo de um projeto existente na base de dados da plataforma, onde a análise foi concentrada no aprimoramento do jogo com a realidade dos conceitos Físicos e na familiarização com a ferramenta online. Na segunda fase, houve a elaboração de novo projeto, voltado à proposta de aplicação, ou seja, no movimento bidimensional ou lançamento oblíquo, atendendo mais rigorosamente às equações do movimento desse sistema.

O estudo tem como público-alvo professores, atuantes na educação básica e ensino superior, estudantes que estão sendo apresentados à disciplina de Física, podendo contemplar os do $9^{\circ}$ ano do ensino fundamental, do $1^{\circ}$ ano do ensino médio e estudantes de graduação em Física ou qualquer outra área das ciências exatas.

\section{Apresentação e desenvolvimento de jogo no Scratch}

A plataforma do Scratch está disponível no site https://scratch.mit.edu/ e permite o acesso a alguns jogos que foram criados por outros usuários. Além de jogar, é possível personalizar o jogo já existente, aumentando assim a identificação com a ferramenta pedagógica. Para criar um jogo, o usuário deve acessar o site, criar uma conta, iniciar um novo projeto e em seguida dar forma ao jogo ou animação. Nessa última etapa, deve-se atribuir um título ao projeto, escolher um plano de fundo ou palco, incluir os personagens ou atores, e por fim, montar as ações. O atrativo desta ferramenta está também na facilidade da construção das ações, pois é feita por meio de programação em blocos, semelhante a construção de um lego.

O Scratch permite a programação das próprias histórias, jogos e animações interativas e o compartilhamento das suas criações com outros na comunidade - isto ajuda os jovens a pensar de forma criativa, a raciocinar sistematicamente e a trabalhar colaborativamente - competências essenciais à vida no século XXI. 


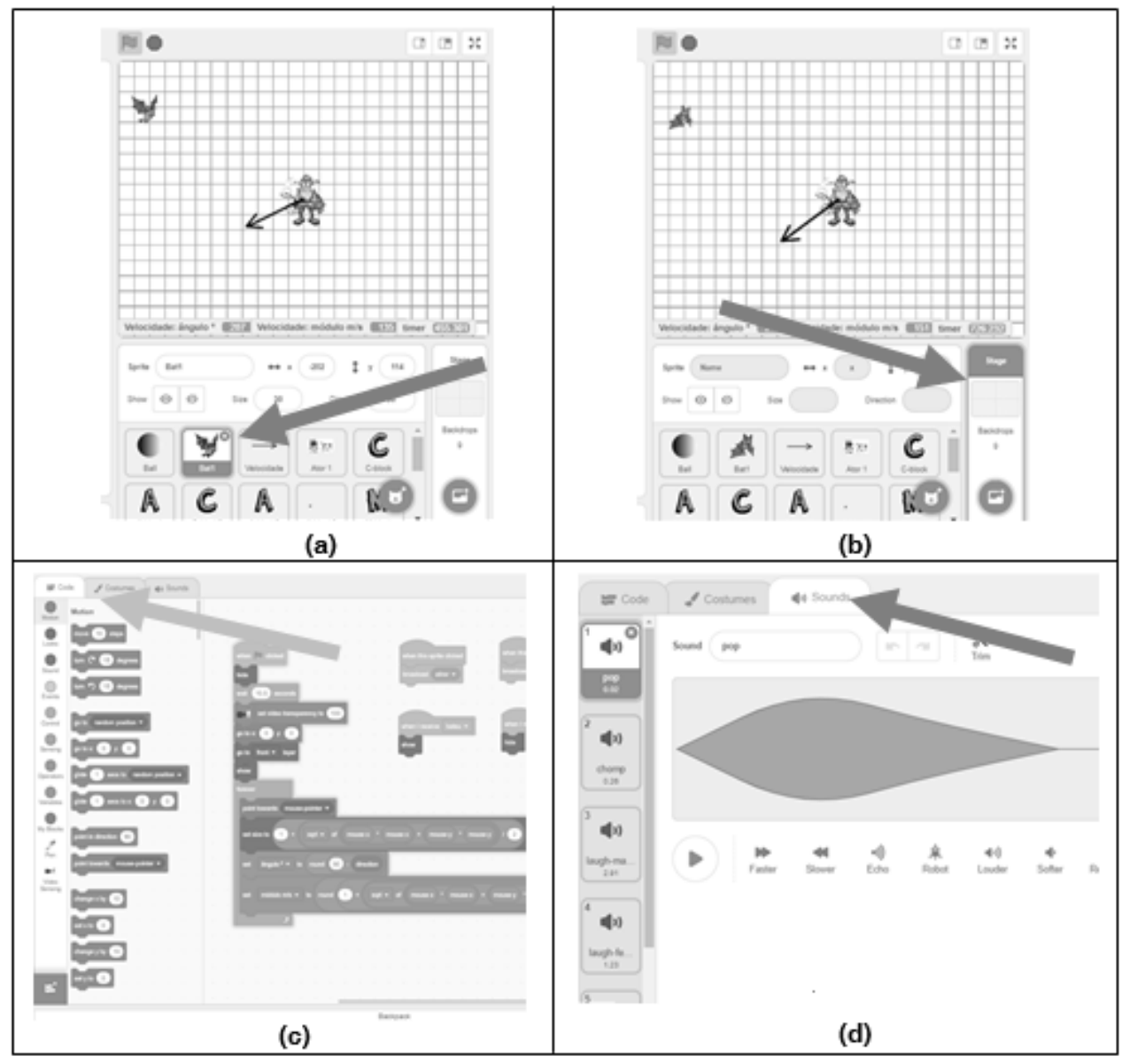

Figura 1: Ambiente do Scratch: a) Atores ou personagens; b) Palco/Plano de fundo; c) Programação e d) sons.

A programação é realizada por meio de blocos gráficos e pode ser feita de forma paralela, ou seja, várias ações podem ocorrer de forma simultânea. A proposta da programação ser realizada em blocos e possuir visualmente cores diferentes em cada comando aproxima o estudante ao entendimento da lógica da programação. A Figura 1(a) mostra, por exemplo, os personagens selecionados para o jogo proposto, o homem e a ave, bem como a escolha do plano de fundo na Figura 1(b). O objetivo do jogo é espantar a ave pelo lançamento de um projétil e, nesse caso, o plano de fundo auxilia a visualizar a trajetória do objeto em movimento.

Outros elementos podem ser incluídos no desenvolvimento do jogo, pois vários recursos estão disponíveis, como movimento, aparência, som, variáveis, controle, sensores e operadores (ver Figura 1(c)). Na paleta Motion da aba Code, podemos controlar a posição e a inclinação de cada objeto. Em looks, determina-se quando o objeto é visível ou oculto, como também a mudança de aparência para causar a impressão de um movimento mais realista. O tópico Sound é apresentado na Figura 1(d) e nele é permitido agregar música ou falas no projeto. Em Variables, guardam-se os valores que se deseja manter na memória para controlar ações, atuando como um ótimo recurso para desenvolver o conceito de incógnita. Já na opção Control, é possível usar funções de lógica e controle de fluxo. Outra ferramenta interessante é a opção Sensing, onde se tem acesso a várias informações, tais como, saber, por exemplo, se houve colisões entre dois personagens ou entre um personagem e a borda da tela. Por fim, em Operators temos acesso a vários operadores matemáticos, como adição, subtração, 
funções etc. Caso haja limitações no acesso à internet, é possível baixar o aplicativo e instalar no computador por meio do endereço https://scratch.mit.edu/download.

\section{Descrição do jogo voltado ao ensino da cinemática}

Descreve-se, nesta seção, duas atividades que foram desenvolvidas: uma adaptação de um jogo já existente e a criação de um novo projeto, a fim de exemplificar e aplicar as possibilidades existentes nessa ferramenta didática.

O jogo da catapulta estava disponível no banco de dados do sistema, possuindo o objetivo de lançar um projétil para atingir o castelo. Este projeto foi modificado e ajustado para que o movimento da catapulta obedecesse às equações básicas do lançamento oblíquo, sem considerar a resistência do ar, mas com a possibilidade da escolha do ângulo, velocidade inicial do lançamento e visualização do percurso da bola lançada. As configurações dos jogos antes e depois dos ajustes são apresentados na Figura 2 (a) e (b).

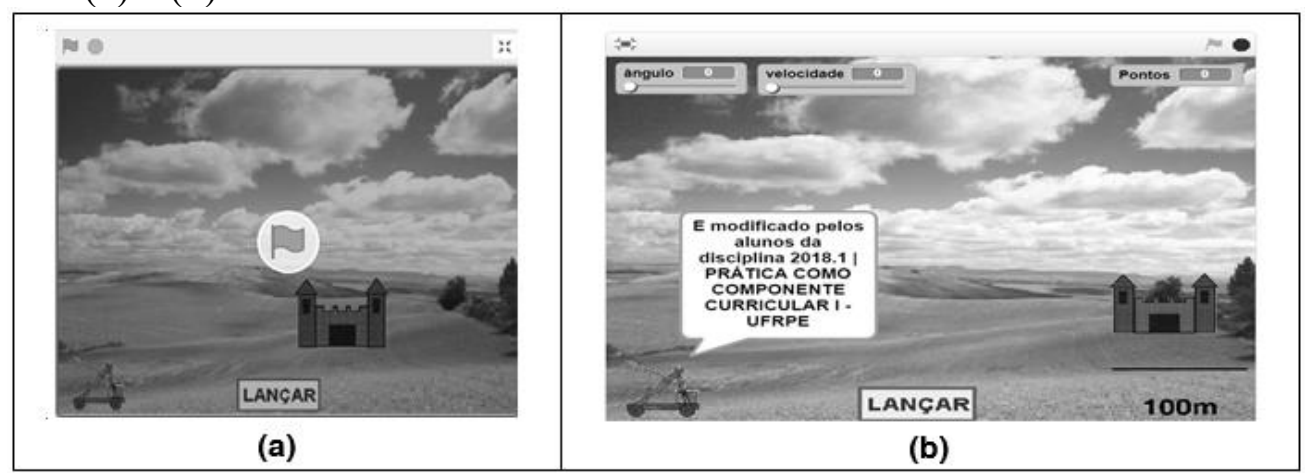

\section{Figura 2: Jogos desenvolvidos: a) Jogo da catapulta original; b) Jogo da catapulta modificado.}

A Figura 3(a), abaixo, mostra parte da programação da bola após as devidas modificações e exemplifica a forma da programação realizada em blocos. Para a programação, definem-se as variáveis do programa através da paleta de código no grupo variables, nomeando as variáveis, conforme o que se deseja realizar. No caso da catapulta, definiu-se como variáveis as grandezas: ângulo, posição e velocidade no plano cartesiano xy. Para explicitar a trajetória da bola na tela, na interface do jogo, esses comandos são realizados com a manipulação do mouse, que definirá a velocidade e o ângulo de lançamento.

O novo projeto, contendo o conteúdo do movimento $2 \mathrm{D}$, foi nomeado como jogo Caça Morcego e seu design gráfico é visto na Figura 3(b). Esta atividade traz a possibilidade de incluir o alvo em movimento a cada vez que uma bola é lançada. 


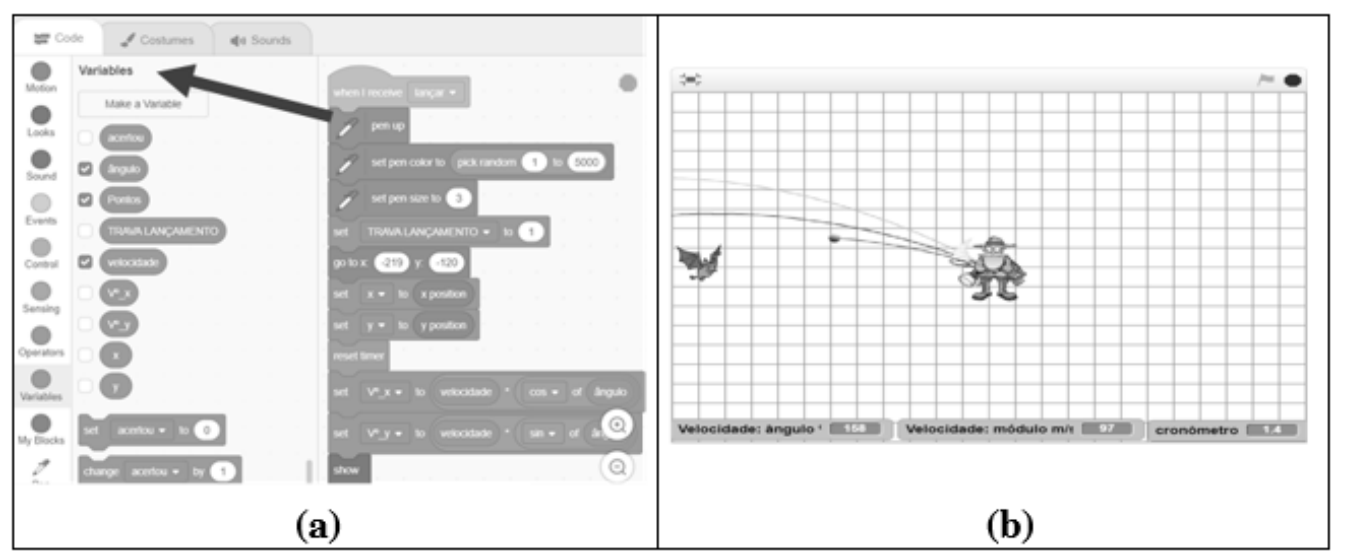

Figura 3: (a) Paleta de Variáveis na plataforma Scratch (à esquerda) e tela da programação à direita; (b) Design gráfico do jogo Caça Morcego.

A cada tentativa, mensagens na tela aparecem fornecendo informações sobre a ave em questão, e alertas sobre a preservação ambiental, assim, questões referentes ao Meio Ambiente, tema transversal, vinculado ao ensino de conceitos físicos. Na tela é exibido um vetor que aponta na direção do mouse e seu tamanho é proporcional ao módulo da velocidade inicial da bola.

A bola é lancaça quando o botão do mouse é pressionado e a trajetória da bola é marcada na tela com determinada cor escolhida de forma aleatória. Quando a bola toca na borda da tela ou toca no morcego, ela é apagada e redesenhada próximo ao caçador. Segundo a programação proposta, o morcego, inicialmente, aparece na tela e toda vez que é atingido desencadeia uma sequência de eventos, que alteram o cenário e os personagens. Caso o morcego não seja atingido, ele permanece no mesmo lugar.

A partir desses exemplos, é possível que os próprios estudantes desenvolvam seus jogos com o uso dessa tecnologia ou modifiquem os jogos apresentados pelos professores.

\section{Resultados esperados}

Os jogos apresentados podem ser utilizados durante as aulas de cinemática e com diversas finalidades. $\mathrm{O}$ ato de jogar pode ser realizado anterior à apresentação do conteúdo, com a finalidade de motivar o estudo, ou ainda posterior a uma aula expositiva em que, nesse caso, serão aplicados os conhecimentos construídos. Numa aula complementar é possível estimular a modificação dos parâmetros dos jogos, bem como a criação de novos projetos, incluindo os conhecimentos de programação.

Com a disponibilização desse jogo e com as possibilidades de aplicação citadas acima, espera-se impactar professores de Física e estudantes interessados ou não na área de exatas ao estudo desta ciência, além de incentivar a utilização de outras tecnologias e elementos da gamificação nas aulas de Física.

\section{Considerações finais}

Este trabalho traz a descrição de dois jogos construídos com a plataforma scratch, ambos abordando os conceitos de lançamento de projéteis em duas dimensões, sendo um a modificação de um jogo já existente e o outro uma nova proposta. Os jogos visam auxiliar professores e estudantes no processo de ensino e aprendizagem dos conteúdos da cinemática. 
Como os jovens estão conectados com a internet, o desenvolvimento de jogos no Scratch pode motivá-los a compartilhar seus programas com os colegas fomentando a socialização da física e outras áreas do saber. Embora não seja necessário conhecer nenhuma linguagem de programação, o sujeito deve desenvolver habilidades de criatividade e criação para poder criar seus próprios jogos ou modificar os já existentes.

\section{Referências}

Araújo, M. S. T; Abib, M. L. V. S. (2003) "Atividades experimentais no ensino de física: diferentes enfoques, diferentes finalidades". In Revista Brasileira de Ensino Física, São Paulo, v. 25, n. 2, p. 176-194.

Ausubel, D. P. (2003) "Aquisição e retenção de conhecimentos: uma perspectiva cognitiva”. Lisboa: Plátano Edições Técnicas.

Fardo, M. L. (2013) “A Gamificação aplicada em ambientes de aprendizagem”. In RENOTE - Revista Novas Tecnologias na Educação, v. 11, n. 1, p 1-9.

Gaspar, A. (2000) "Física: mecânica”. São Paulo: Ática.

LEAD Project. (2014) “Super Scratch Programming Adventure!” 2. ed. USA: No Starch Press.

Lima, A. P. A. B. (2010) “Psicologia II”. Recife: UFRPE/UAEADTec.

Moreira, M.A. (2017) "Grandes desafios para o ensino da Física na educação contemporânea”.In Revista do Professor de Física, v. 1, n. 1, p. 1-13.

Pelizzari et al. (2002) "Teoria da aprendizagem significativa segundo Ausubel”. In Revista PEC, Curitiba, v. 2, n.1, p. 37-42.

Sasaki, D.G.G.; Jesus, V.L.B. (2017) "Avaliação de uma metodologia de aprendizagem ativa em óptica geométrica através da investigação das reações dos alunos". In Revista Brasileira de Ensino de Física, v. 39, n. 2, e2403 1-10.

Silva, E. O. (2014) "Conversando sobre ciência”. Ribeirão Preto: Sociedade Brasileira de Genética.

Silva, J. B.; Sales, G. L.; Castro, J. B. (2019) "Gamificação como estratégia de aprendizagem ativa no ensino de Física". In Revista Brasileira de Ensino Física, São Paulo, v. 41, n. 4, e20180309 1-9. 